AIAA-2002-1743

\title{
APPLICATION OF INTERFACE TECHNOLOGY IN PROGRESSIVE FAILURE ANALYSIS OF COMPOSITE PANELS
}

\author{
D. W. Sleight" and C. G. Lotts ${ }^{\dagger}$ \\ NASA Langley Research Center, Hampton, VA 23681-0001, U.S.A.
}

\begin{abstract}
$\underline{\text { Abstract }}$
A progressive failure analysis capability using interface technology is presented. The capability has been implemented in the COMET-AR finite element analysis code developed at the NASA Langley Research Center and is demonstrated on composite panels. The composite panels are analyzed for damage initiation and propagation from initial loading to final failure using a progressive failure analysis capability that includes both geometric and material nonlinearities. Progressive failure analyses are performed on conventional models and interface technology models of the composite panels. Analytical results and the computational effort of the analyses are compared for the conventional models and interface technology models. The analytical results predicted with the interface technology models are in good correlation with the analytical results using the conventional models, while significantly reducing the computational effort.
\end{abstract}

\section{$\underline{\text { Introduction }}$}

Composite structures can develop local failures or exhibit local damage such as matrix cracks, fiber breakage, fiber-matrix debonds, and delaminations under normal operating conditions which may contribute to their failure. The ability to predict the initiation and growth of such damage is essential for predicting the performance of composite structures and developing reliable and safe designs. Hence, the need for a reliable and efficient methodology capable of determining the residual strength after the initiation and propagation of damage in composite structures is of great importance.

In the past years Pifko ${ }^{1}$, Moas $^{2}$, and Sleight et $\mathrm{al}^{3,4}$ have implemented a progressive failure analysis procedure into a research finite element code, COMET$\mathrm{AR}^{5}$, developed at the NASA Langley Research Center. COMET-AR is a general-purpose finite element analysis system used as a research testbed for new methodologies which have included finite element formulations, constitutive modeling, adaptive refinement, and equation solution techniques. The progressive failure analysis procedure evaluates ply-byply failure through the laminate and discounts the material properties for any ply with failures. Using COMET-AR's nonlinear solution procedure, the progressive failure analysis can include both material nonlinearity due to the degradation of material properties and geometric nonlinearity due to large deformations.

In recent years, a method for connecting finite element models without the use of transition modeling has been developed and implemented into COMET-AR. This method called interface technology ${ }^{6-8}$ is an improved technique for connecting dissimilar meshed substructures to form a single finite element model. Modeling with interface technology eliminates the need for using transition elements to connect substructures with different mesh densities. The interface technology enables local model refinements, model repairs, and assembly of incompatible models as shown in Figure 1. In the design process of complex composite structures, critical regions may require remeshing multiple times due to various design changes. Hence, the elimination of transition meshing between the critical regions and the noncritical regions can significantly shorten both the analyst effort and the design time.

The application of interface technology to linear and nonlinear structural analyses been investigated and its advantages over conventional meshing have been well documented $^{9-11}$. However, interface technology has not been demonstrated in the progressive failure analysis of composite structures. The objective of this paper is to apply the interface technology in the progressive failure analysis of composite panels. The analytical results and the computational effort from progressive failure analyses using the interface technology are compared with those from conventional models (without interface technology). The computational improvements of the use of interface technology in progressive failure analyses will be demonstrated while providing accurate results.

\section{Progressive Failure Methodology}

\footnotetext{
* Aerospace Engineer, Analytical and Computational Methods Branch, Member AIAA.

${ }^{中}$ Aerospace Engineer, Analytical and Computational Methods Branch.

Copyright $\mathrm{O} 2002$ by the American Institute of Aeronautics and Astronautics, Inc. No copyright is asserted in the United States under title 17, U.S. Code. The U.S Government has a royalty-free license to exercise all rights under the copyright claimed herein for Governmental Purposes. All rights are reserved by the copyright owner.
} 
The methodology for performing a progressive failure analysis in COMET-AR is shown in Figure 2. Using a finite element model with an initial displacement $u_{0}$ and specified boundary conditions (B.C.'s), a nonlinear analysis is performed to account for geometrical and material nonlinearities (due to past material failures) until a converged equilibrium state is obtained. Nonlinear analysis iterations are performed to establish equilibrium using a constant set of material properties. Then at the converged solution, the ply stresses are determined and evaluated for failure at material points within every element according to a failure criterion. If a failure is detected, as indicated by the chosen failure criterion, the material properties at that material point are changed according to the material degradation method. The solution step is then incremented by a small displacement increment to the next displacement level and the process is repeated with a new set of material properties. In COMET-AR, equilibrium is not re-established after degrading the material properties. A small displacement increment is used instead to minimize the effect of not reestablishing equilibrium. When convergence of the nonlinear analysis solution procedure cannot be achieved, the final failure load has been reached unless the analysis is restarted (with a smaller displacement increment or larger convergence tolerance). Details of the failure criterion, material degradation model, and nonlinear analysis procedure used in COMET-AR's progressive failure analysis capability are provided in the following sections.

\section{$\underline{\text { Failure Criterion }}$}

Hashin $^{12}$ introduced a stress-based failure criterion that can predict distinct failures modes. The Hashin criterion considers four distinct failure modes, tension and compressive fiber and matrix modes, which are modeled separately to determine failures. The failure criteria are summarized as follows:

Tensile Fiber Mode, $\sigma_{11}>0$

$$
\left(\frac{\sigma_{11}}{X_{T}}\right)^{2}+\left(\frac{\tau_{12}}{S_{A}}\right)^{2} \geq 1
$$

Compressive Fiber Mode, $\sigma_{11}<0$

$$
\left(\frac{\sigma_{11}}{X_{C}}\right)^{2} \geq 1
$$

Tensile Matrix Mode, $\sigma_{22}>0$

$$
\left(\frac{\sigma_{22}}{Y_{T}}\right)^{2}+\left(\frac{\tau_{12}}{S_{A}}\right)^{2} \geq 1
$$

Compressive Matrix Mode, $\sigma_{22}<0$

$$
\frac{\sigma_{22}}{Y_{C}}\left[\left(\frac{Y_{C}}{2 S_{T}}\right)^{2}-1\right]+\left(\frac{\sigma_{22}}{2 S_{T}}\right)^{2}+\left(\frac{\tau_{12}}{S_{A}}\right)^{2} \geq 1
$$

The principal stresses and strength properties of a ply used in the failure modes are defined as

$\sigma_{11}, \sigma_{22}$, and $\tau_{12}$ : stress in the fiber direction, stress in the matrix direction, and the in-plane shear stress, respectively.

$X_{T}$ and $X_{C}: \quad$ tensile and compressive strengths in the fiber direction.

$Y_{T}$ and $Y_{C}$ : tensile and compressive strengths in the matrix direction.

$S_{A}$ and $S_{T}$ : in-plane shear strength and transverse shear strength, respectively.

The failure criteria are evaluated at each material point in the composite structure. A material point is a location within the laminate thickness (possibly several points in each ply) and at a given surface location that is defined by a surface integration point or Gauss point for a specific shell element. In this paper, each ply in the laminate is integrated with three points through the thickness by Simpson's rule. The finite element used in the progressive failure analysis is a 4-node quadrilateral shell element based upon the Kirchhoff-Love shell theory and is denoted as the ES5/E410 element ${ }^{13}$ in the COMET-AR code. The ES5/E410 element has five inplane Gauss points. Therefore, the ES5/E410 element has a total of $3 \times 5 \times$ Number-of-Plies material points that are checked for failure in an element. For example, a 16-ply laminate would have $3 \times 5 \times 16=240$ material points per element. The failure modes are used to determine which material properties of the failed material point are degraded for the next step in the progressive failure analysis.

\section{Material Degradation Model}

The material degradation model is based on ply discounting where ply properties are discretely reduced from their initial elastic value. The elastic material properties can be degraded recursively each solution step by a fixed material degradation factor or the properties can be instantaneously degraded to zero in a single solution step. The material properties are degraded only at the material points where failure is indicated. The material properties are archived for use 
in subsequent calculations. Here the elastic material properties that are degraded are based upon the failure modes of the Hashin failure criterion. The moduli $E_{11}$ and $G_{12}$ and the Poisson's ratio $v_{12}$ are degraded when fiber failure is detected. The material properties $E_{22}$, $G_{12}$, and $v_{12}$ are degraded when matrix failure is detected. Each material point has a set of nine state variables that include the degraded material property values and failure mode flags. Thus, the 16-ply laminate would archive $240 \times 9=2160$ state variables per element. It is easy to see that for large models the data storage requirements could be significant.

\section{Nonlinear Analysis}

In the progressive failure analysis of a composite structure, both the geometrical nonlinearity and material nonlinearity must be considered. Using COMET-AR's nonlinear solution procedure, the analysis can include both geometric nonlinearity due to large deformations and material nonlinearity due to degradation of material properties.

The nonlinear finite element system equations can be written as

$$
f^{i n t}(u, \lambda)=f^{e x t}(\lambda)
$$

where $f^{n t}$ is the nonlinear internal force vector for the finite element system, $f^{\text {ext }}$ is the external force vector, $\boldsymbol{u}$ is the displacement vector, and $\lambda$ is the load factor.

The Newton-Raphson (N-R) method is used to solve the system of equations in Eq. 5 by linearizing at each load level. This linearization leads to the solution of the following linear equations,

$$
\begin{gathered}
\boldsymbol{K}_{T n+1}^{(i)} \Delta \boldsymbol{u}^{(i+1)}=\boldsymbol{R}_{n+1}^{(i)} \\
\boldsymbol{u}_{n+1}^{(i+1)}=\boldsymbol{u}_{n+1}^{(i)}+\Delta \boldsymbol{u}^{(i+1)}
\end{gathered}
$$

within an iteration loop where $n+1$ is the current solution step, $i+1$ is the iteration number at that solution step, and $\Delta \boldsymbol{u}$ is the iterative displacement change. $\boldsymbol{R}$ is the force imbalance vector given by

$$
\boldsymbol{R}_{n+1}^{(i)}=f^{e x t}\left(\lambda_{n+1}\right)-f^{i n t}\left(\boldsymbol{u}_{n+1}^{(i)}, \lambda_{n+1}\right)
$$

and $\boldsymbol{K}_{T}$ is the tangent stiffness matrix which is function of $\boldsymbol{u}$ and $\lambda$. In the full N-R method, the tangent stiffness matrix is updated after each iteration, whereas in the modified N-R method, the tangent stiffness matrix is updated at the beginning of each converged solution step. The progressive failure analysis in COMET-AR employs the modified N-R method using displacement control to establish equilibrium in Eq. 6. Under displacement control, the displacement is incremented by a constant displacement during the iteration, and a new solution is found.

The modified N-R is an iterative process, which requires computing the new displacement increment $\Delta \boldsymbol{u}$ in Eq. 6 for the current solution step $n+1$ using the current tangent stiffness matrix. The displacement vector $\boldsymbol{u}$ is then updated by Eq. 7 for the $i+1$ iteration using $\boldsymbol{\Delta} \boldsymbol{u}$. The force imbalance vector $\boldsymbol{R}$ is then updated in Eq. 8 with the new displacement solution and the solution process is continued for the next iteration. In the nonlinear analysis iterations, a constant set of material properties are used. This solution process is continued until convergence is achieved by reducing the force imbalance $\boldsymbol{R}$, and consequently $\Delta \boldsymbol{u}$, to within some specified tolerance using the strain-energy convergence criteria ${ }^{5}$. Once convergence is achieved at a solution step, the failure criterion is assessed and the material properties are degraded at the material points if failures are detected. The nonlinear analysis is then advanced to the next solution step by a small displacement increment and the tangent stiffness matrix is recomputed. The tangent stiffness matrix will then reflect the failures from the previous solution step. Because of the discrete changes in the local stiffness matrix due to material property degradation, the nonlinear solution strategy often expends significant computational effort for each solution step.

\section{$\underline{\text { Interface Technology }}$}

Interface technology connects independently modeled finite element substructures along their common boundaries. A general description of interface technology and the overview of the implementation strategy can be found in references 6-8. The interface technology provides for the interaction and load transfer between non-coincident nodes along the substructure interface boundaries. This approach couples the finite element substructure using an independent displacement function at the interface between the substructures, which eliminates the need for transition modeling. The coupling of finite element substructures with noncoincident nodes is accomplished through an interface element between the substructures using a hybrid variational formulation ${ }^{8}$ as shown in Figure 3. The interface element $\Gamma_{I}$ is discretized with a mesh of evenly spaced pseudo-nodes (open circles in the figure), which need not be coincident with any of the interface nodes (filled circles in the figure) of the substructures. The hybrid variational formulation employs an integral form for the compatibility between the interface element 
and finite element substructures, $\Omega_{1}$ and $\Omega_{2}$.

The interface technology has been implemented into the COMET-AR finite element analysis code and has been shown to maintain solution accuracy for a wide range of applications ${ }^{9-11}$. The method was demonstrated in linear analyses in reference 10 and nonlinear analyses in references 9 and 11 .

\section{Analysis Results}

Progressive failure analyses of two composite panels under two different loading conditions are performed. Comparisons are made between the progressive failure results (percentage of element failure and loaddeflection response) and computational effort for the analyses using conventional models and the results and computational effort for interface technology models. In quantifying the failure state, the percentage of element failure is used. This percentage is defined as the number of material points with failures within an element divided by total number of material points in the element. The progressive failure analysis results for the conventional models were reported in references ${ }^{3,4,14}$ and the results compared very well with test results. Mesh convergence studies for the conventional models were performed in reference 3 . The conventional models were then modified incorporating the interface technology in regions where failures would occur. The ES5/E410 element in COMET-AR was used in all analyses. The modified N-R method with displacement control (constant displacement increments) was used with the total strain-energy convergence criteria and a convergence tolerance of 0.001 . In all progressive failure analyses, the Hashin failure criterion was used with a material degradation factor set to ten percent. That is, if a failure was detected, the material properties associated with that failure mode were degraded to ten percent of their previous values ${ }^{3}$. All analyses were performed on an IBM RS/6000 7044 Model 270 workstation with four $375 \mathrm{MHz}$ POWER3-II processors, 2 Gbytes of memory, and 120 Gbytes of disk storage.

\section{$\underline{\text { Tension-Loaded Panel with Hole }}$}

A tension-loaded composite panel with an open hole $\mathrm{e}^{15,16}$ is analyzed with the progressive failure analysis capability. The panel, shown in Figure 4, is 8 -inches long and 1 -inch wide with a central circular 0.25 -inchdiameter hole. The panel is fabricated with T300/1034C graphite/epoxy with a lay-up of $\left[0 /( \pm 45)_{3} / 90_{3}\right]_{s}$ and ply thickness of 0.00515 inches. The ply properties for the panel from Chang and Chang ${ }^{15}$ are given in Table 1. The sides of the panel are free and one end is fixed as shown in Figure 4. A tensile uniform displacement $\delta$ is applied to the opposite end.

The conventional and interface technology models for the tension-loaded panel with a hole are shown in Figures 5(a) and (b), respectively. Both models have the same mesh density in the region near the open hole. However, the interface technology model has a coarser mesh density in the surrounding region. The conventional model has 768 elements and 4908 degrees of freedom (DOF), whereas the interface technology model has 432 elements and 3316 DOF.

The panel was analyzed using the conventional and interface technology models. A constant displacement increment of 0.01 inches was applied to both models in the progressive failure analyses. The resultant load $P$ as a function of the applied displacement $\delta$ is shown in Figure 6 for both models. The load-deflection response indicates that the results from both analyses are nearly identical. The conventional model exhibited final failure at 3,214 lbs. and the interface technology model exhibited final failure at 3,185 lbs. The final failure load for this panel is reported to be $3,523 \mathrm{lbs}$. by $\operatorname{Tan}^{16}$. The percentage of element failure at the final failure load of both models is shown in Figure 7. Figures 7(a) and 7(b) display close-up views of the failure region surrounding the hole. The results indicate that for this panel there is little difference between the conventional model (Figure 7(a)) and the interface technology model (Figure 7(b)) in the failed region surrounding the hole.

Table 2 contains a summary of the number of degrees of freedom (DOF), the computational (CPU) run-time required, and the computational database file size for both the conventional and interface technology models. The table also gives the reduction in CPU runtime and computational database size due to the use of interface-technology models. The reduction in the CPU run-time was $37 \%$ and the reduction in computational database size was $33 \%$.

\section{Compression-Loaded Panel with Hole}

A compression-loaded panel with an offset circular hole is also analyzed with the progressive failure analysis capability. The panel, shown in Figure 8, is denoted as "Panel H4" in the test results reported by Starnes and Rouse ${ }^{17}$. The panel length is 20.0 inches, and the width is 5.5 inches. The hole is offset from the panel center in the x-direction (7.5 inches from the bottom of the panel) such that it is at or near a buckle crest. The panel is fabricated from T300/5208 graphite/epoxy with a lay-up of $[ \pm 45 / 0 / 90 / \pm 45 / 0 / 90 / \pm 45 / 0 / 90]_{\mathrm{s}}$ and a ply thickness of 0.00574 inches. The ply properties from Starnes and Rouse $^{17}$ are given in Table 1. The top edge of the panel 
is clamped by fixtures and the two side edges are simply supported by knife-edge supports to prevent widecolumn buckling of the panel. A uniform compressive displacement $\delta$ is applied at the bottom of the panel.

The conventional and interface technology models for the compression-loaded panel with hole are shown in Figures 9(a) and (b), respectively. Both models have the same mesh density in the region near the open hole. However, the interface technology model has a coarser mesh density in the surrounding region. The conventional model has 736 elements and 4,458 DOF, whereas the interface technology model has 301 elements and 2,154 DOF.

The panel was analyzed using the conventional and interface technology models. An initial imperfection was imposed on this panel to advance the progressive failure analysis into the postbuckling region. This imperfection was obtained by normalizing the first buckling mode shape by its maximum component, scaling that value by $5 \%$ of the panel thickness, and adding the result to the nodal coordinates. The imperfection is added to the initial geometry to allow efficient progress past the critical buckling point, but does not affect the results in the postbuckling range. An initial displacement of 0.001 inches was applied to the panel with a displacement increment of 0.0025 inches. In both analyses, the nonlinear analysis had to be restarted with the convergence tolerance increased to 0.005 at a displacement level of 0.069 inches in order for the progressive failure analyses to continue.

The resultant load $P$ as a function of the applied displacement $\delta$ is shown in Figure 10 for both models. The load-deflection response for both analyses closely match each other until a displacement level of approximately 0.070 inches is reached. After that displacement level, the results from the conventional model slightly over-predict the final failure compared with the interface technology analysis results. One possible explanation for this disagreement is that when the analyses were restarted with a relaxed tolerance, the solutions went onto different equilibrium paths. Both models correlate well with the test results. The conventional model exhibited final failure at 22,368 lbs. and the interface technology model exhibited final failure at 22,261 lbs. The final failure load from the test is reported to be $21,104 \mathrm{lbs}$. by Starnes and Rouse ${ }^{17}$. The percentage of element failure at the final failure load of both models is shown in Figure 11. Figures 11(a) and 11(b) display close-up views of the failure region surrounding the hole. The conventional model exhibited a slightly larger percentage of element failure around the hole region than the interface technology model.

A summary of the number of degrees of freedom (DOF) and computational effort for both the conventional and interface technology models is provided in Table 2. The table also gives the reduction in CPU run-time and computational database size gained by the use of interface technology models. The reduction in the CPU run-time was $54 \%$ and the reduction in computational database size was $52 \%$.

\section{Concluding Remarks}

A progressive failure analysis capability using the interface technology is presented in this paper. The interface technology, which is a method for comnecting independently modeled finite element substructures along their common boundaries, is utilized in conjunction with progressive failure analysis of composite panels. Two composite panels, a tensionloaded panel with a hole and a compression-loaded panel with a hole, were analyzed with the progressive failure analysis/interface technology capability and their analytical results and computational effort were compared with the results using conventional models (without the interface technology).

The analytical results documented in this paper demonstrate that the interface technology can be a useful tool for the damage prediction of composite structures. The analytical results using the interface technology models correlate well with the results using the conventional models. The most promising benefit of the use of interface technology in progressive failure analysis is the reduction in the number of elements in the model and the associated reduction in data storage requirements and computational run-time. In general, the reduction in computational effort is related to the reduction in the number of degrees of freedom in the model. The greatest benefit was seen in the analysis of the compression-loaded panel with a hole, which had a $54 \%$ reduction in CPU run-time and a $52 \%$ reduction in computational database file size. This significant reduction in computational effort could be very helpful in the progressive failure analysis of full-scale composite structures with a large number of degrees of freedom. 


\section{$\underline{\text { References }}$}

1. Pifko, A. B., "Novel Composites for Wing and Fuselage Applications," Presentation performed under NASA Contract NAS1-18784, Grumman Aerospace Corporation, 1992-1994.

2. Moas, E., "Progressive Failure Analysis of Laminated Composite Structures," Ph.D. Dissertation, Virginia Polytechnic Institute and State University, 1996.

3. Sleight, D. W., "Progressive Failure Analysis Methodology for Laminated Composite Structures," M.S. Thesis, Old Dominion University, 1996.

4. Sleight, D. W., Knight, N. F., Jr., and Wang, J. T., "Evaluation of a Progressive Failure Analysis Methodology for Laminated Composite Structures," 38th AIAA/ASME/ASCE/AHS/ASC Structures, Structural Dynamics, and Materials Conference, AIAA Paper No. 97-1187, 1997.

5. Moas, E., Editor, COMET-AR User's Manual, NASA CR-97-206248, 1997.

6. McCleary, S. L., and Aminpour, M. A., A Generic Interface Element for COMET-AR, NASA CR$195075,1995$.

7. Ransom, J. B., McCleary, S. L., and Aminpour, M. A., "A New Interface Element for Connecting Independently Modeled Substructures," 34th AIAA/ASME/ASCE/AHS/ASC Structures, Structural Dynamics, and Materials Conference, AIAA 93-1503, 1993.

8. Aminpour, M. A., Ransom, J. B., and McCleary, S. L., "A Coupled Analysis for Structures with Independently Modeled Finite Element Subdomains," International Joumal for Numerical Methods in Engineering, Vol. 38, 1995, pp. $3695-$ 3718.

9. Ransom, J. B., "Interface Technology for Geometrically Nonlinear Analysis of Multiple Connected Subdomains," 38th AIAA/ASME/ASCE/AHS/ASC Structures, Structural Dynamics, and Materials Conference, AIAA 97-1298, 1997.

10. Aminpour, M. A., Krishnamurthy, T., McCleary, S.
L., and Baddourah, M. A., "Application of New Interface Element to the Global/Local Analysis of a Boeing Composite Crown Panel," Proceedings of the Fourth NASA/DoD Advanced Composites Technology Conference, NASA CP 3229, pp. 773$788,1993$.

11. Wang, J. T., and Ransom, J. B., "Application of Interface Technology in Nonlinear Analysis of a Stitched/RFI Composite Wing Stub Box," 38th AIAA/ASME/ASCE/AHS/ASC Structures, Structural Dynamics, and Materials Conference, AIAA 97-1190, 1997.

12. Hashin, Z., "Failure Criteria for Unidirectional Fiber Composites," ASME Journal of Applied Mechanics, Vol. 47, June 1980, pp. 329-334.

13. Rankin, C. C., and Brogan, F. A., The Computational Structural Mechanics Testbed Structural Element Processor ES5: STAGS Shell Element, NASA CR-4358, 1991.

14. Wang, J. T., Lotts, C. G., and Sleight, D. W., "Analysis of Discrete-Source Damage Progression in a Tensile Stiffened Composite Panel," 38th AIAA/ASME/ASCE/AHS/ASC Structures, Structural Dynamics, and Materials Conference, AIAA 97-1298, 1997.

15. Chang, F. K., and Chang, K. Y., A Progressive Damage Model for Laminated Composites Containing Stress Concentrations. Journal of Composite Materials, Vol. 21, September 1987, pp. 834-855.

16. Tan, S. C., "A Progressive Damage Model for Composite Laminates Containing Openings," Journal of Composite Materials, Vol. 25, May 1991, pp. 556-577.

17. Starnes, J. H., Jr., and Rouse, M., "Postbuckling and Failure Characteristics of Selected Flat Rectangular Graphite-Epoxy Plates Loaded in Compression," AIAA Paper 81-0543, 1981. 
Table 1- Material Properties.

\begin{tabular}{|l|c|c|c|}
\hline & Symbol & T300/1034-C & T300/5208 \\
\hline Longitudinal Young's Modulus & $E_{11}$ & $21.3 \mathrm{Msi}$ & $19.0 \mathrm{Msi}$ \\
\hline Transverse Young's Modulus & $E_{22}$ & $1.65 \mathrm{Msi}$ & $1.89 \mathrm{Msi}$ \\
\hline Poisson's Ratio & $v_{12}$ & 0.30 & 0.38 \\
\hline In-Plane Shear Modulus & $G_{12}$ & $0.897 \mathrm{Msi}$ & $0.93 \mathrm{Msi}$ \\
\hline Longitudinal Tensile Strength & $X_{T}$ & $251.0 \mathrm{ksi}$ & $200.0 \mathrm{ksi}$ \\
\hline Longitudinal Compression Strength & $X_{C}$ & $200.0 \mathrm{ksi}$ & $165.0 \mathrm{ksi}$ \\
\hline Transverse Tensile Strength & $Y_{T}$ & $9.65 \mathrm{ksi}$ & $11.74 \mathrm{ksi}$ \\
\hline Transverse Compression Strength & $Y_{C}$ & $38.9 \mathrm{ksi}$ & $27.41 \mathrm{ksi}$ \\
\hline Shear Strengths & $S_{A}=S_{T}$ & $19.4 \mathrm{ksi}$ & $10.0 \mathrm{ksi}$ \\
\hline
\end{tabular}

Table 2- Comparison of Computational Effort Between Conventional and Interface Technology Models.

\begin{tabular}{|c|c|c|c|c|c|c|c|c|}
\hline \multirow{2}{*}{ Model } & \multicolumn{3}{|c|}{ Conventional Model } & \multicolumn{2}{c|}{ Interface Technology Model } & \multicolumn{2}{c|}{ Reduction } \\
\cline { 2 - 9 } & DOF & $\begin{array}{c}\text { CPU } \\
(\mathrm{sec})\end{array}$ & $\begin{array}{c}\text { Database } \\
(\mathrm{MB})\end{array}$ & DOF & $\begin{array}{c}\text { CPU } \\
(\mathrm{sec})\end{array}$ & $\begin{array}{c}\text { Database } \\
(\mathrm{MB})\end{array}$ & CPU & Database \\
\hline $\begin{array}{c}\text { Tension-Loaded } \\
\text { Hole Panel }\end{array}$ & 4908 & 1754 & 57 & 3316 & 1111 & 38 & $37 \%$ & $33 \%$ \\
\hline $\begin{array}{c}\text { Compression-Loaded } \\
\text { Panel with Hole }\end{array}$ & 4458 & 5180 & 140 & 2154 & 2366 & 67 & $54 \%$ & $52 \%$ \\
\hline
\end{tabular}
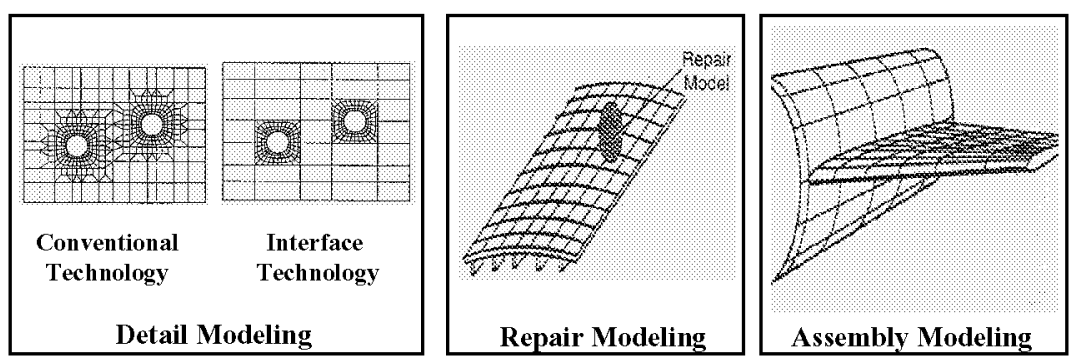

Figure 1- Applications of interface technology.

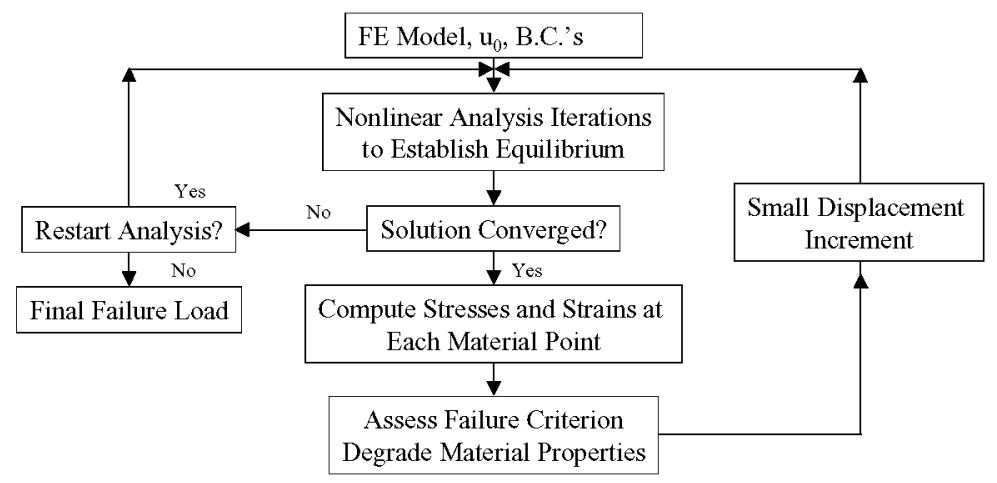

Figure 2- Progressive failure analysis methodology. 


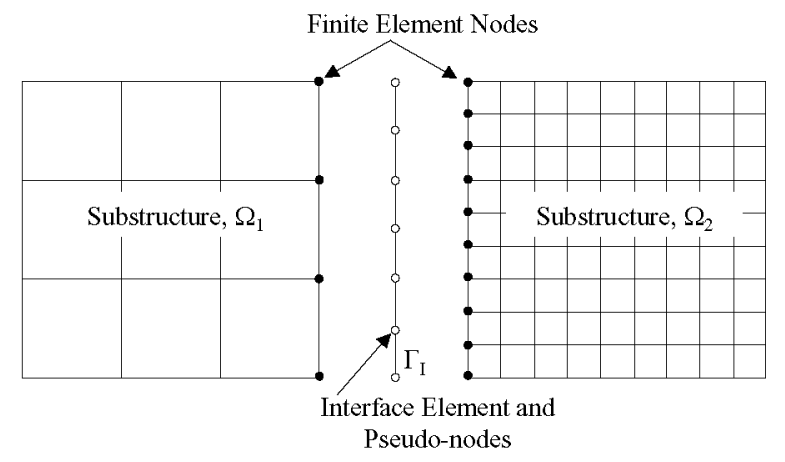

Figure 3- Interface element concept.

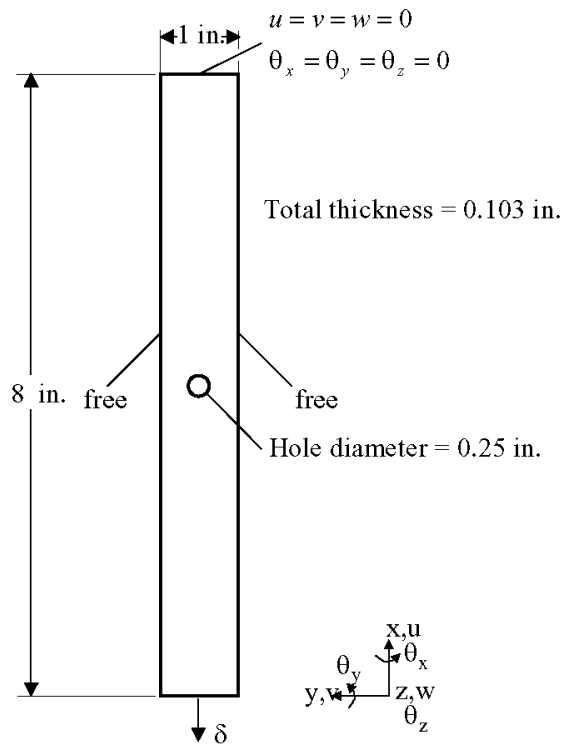

Figure 4- Geometry and boundary conditions of tension-loaded panel with hole.

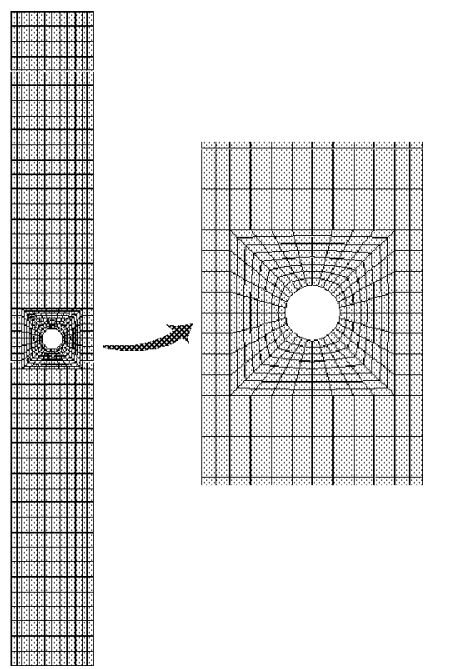

(a) Conventional model

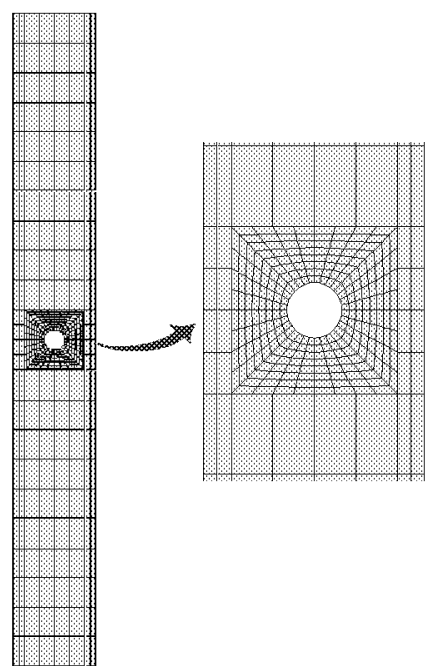

(b) Interface technology model

Figure 5- Finite element models of tension-loaded panel with hole. 


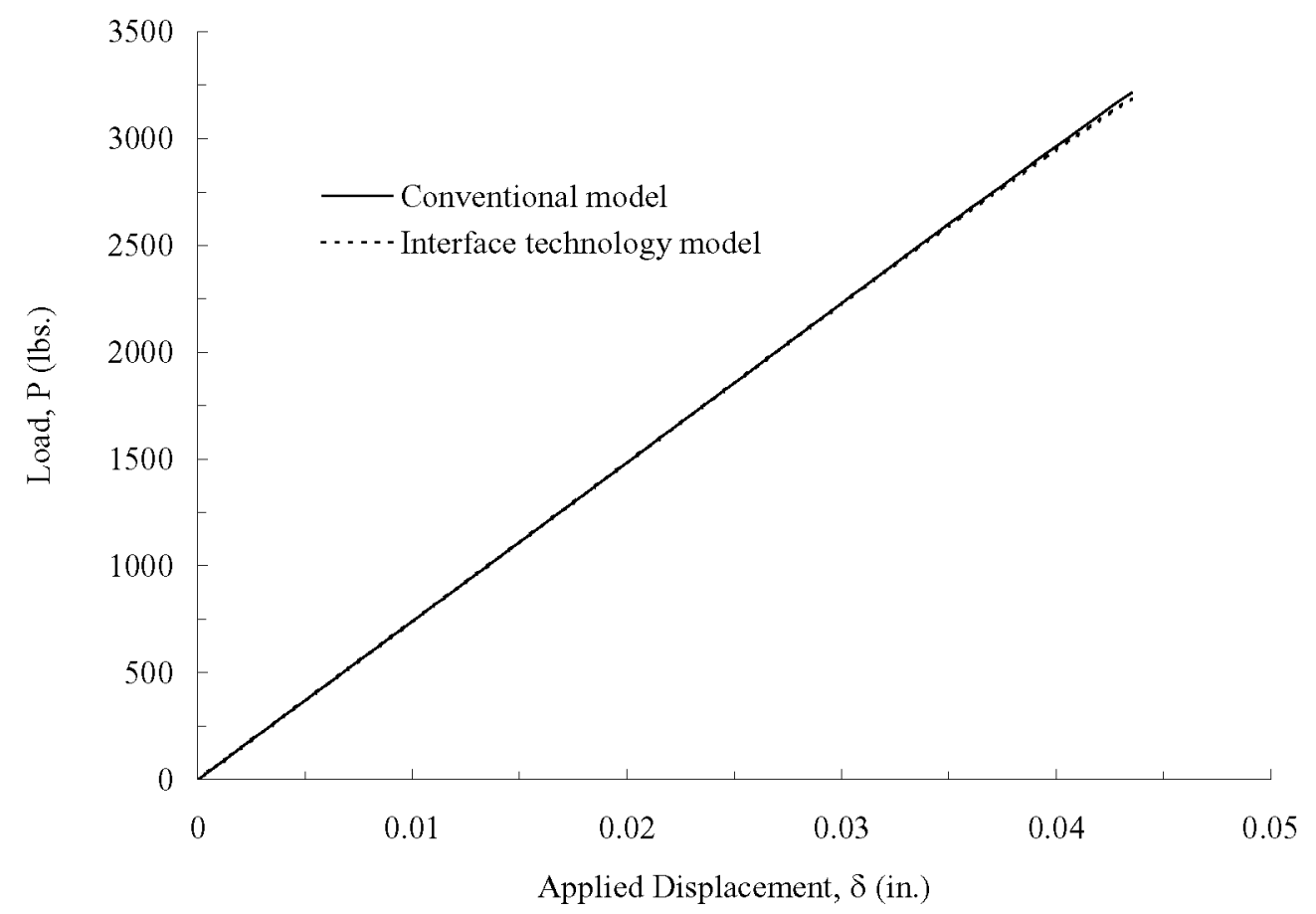

Figure 6- Load-deflection response for tension-loaded panel with hole.

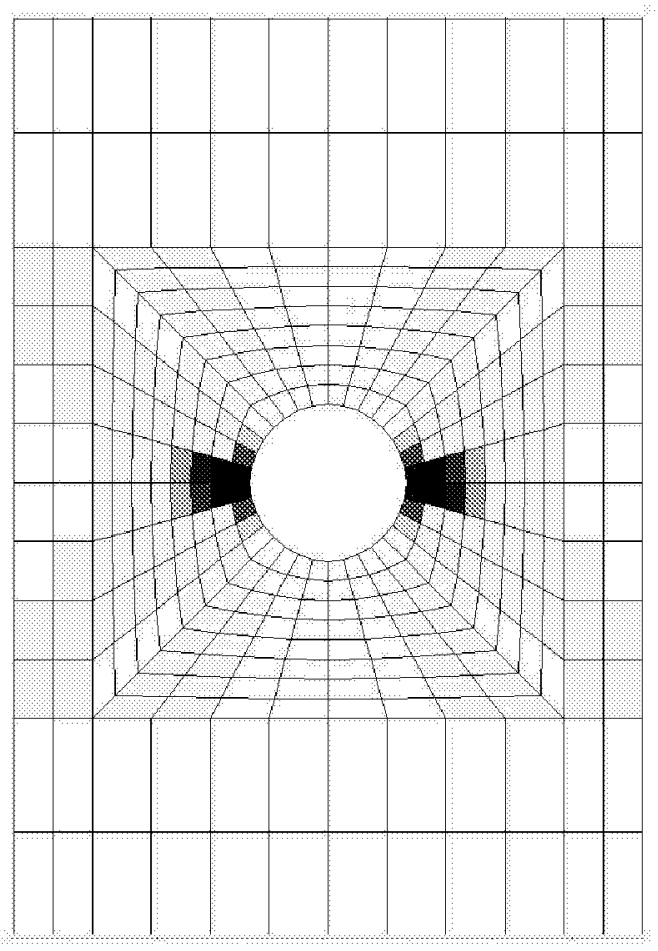

(a) Conventional model

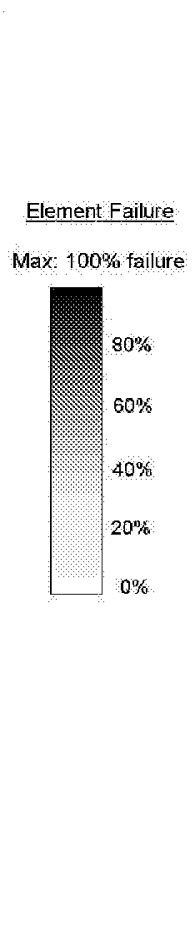

Figure 7-Percentage of element failure of tension-loaded panel with hole at final failure.

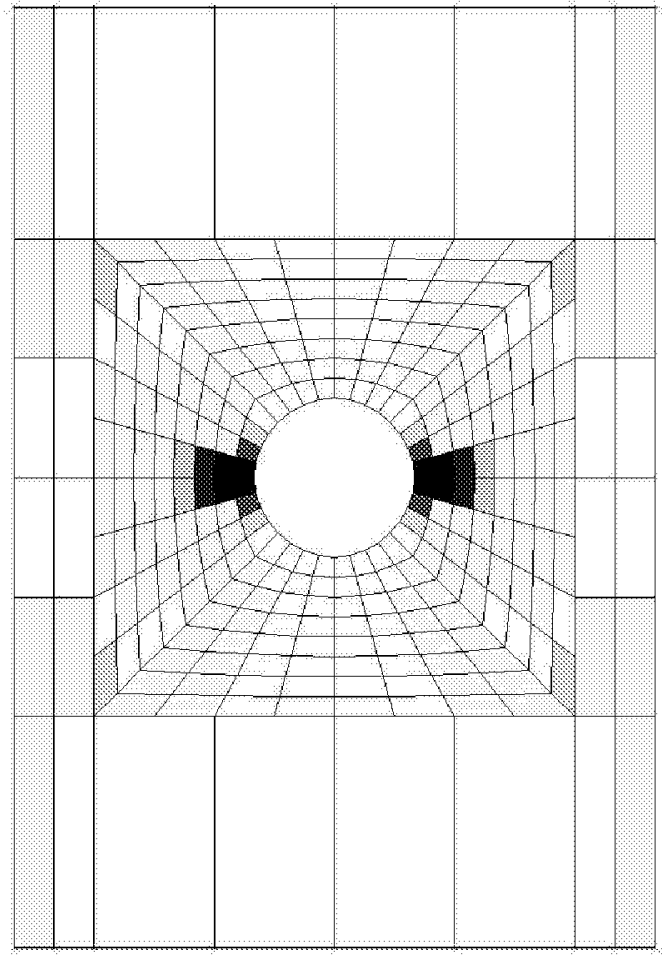

(b) Interface technology model 


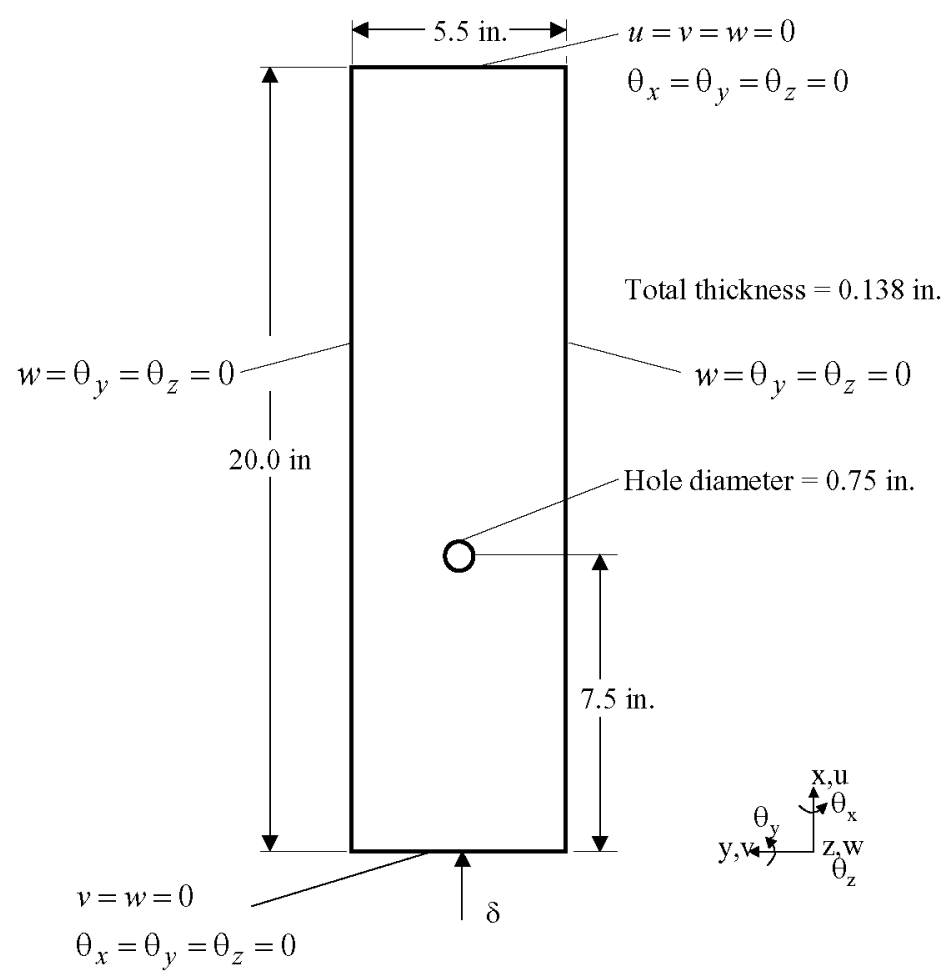

Figure 8- Geometry and boundary conditions of compression-loaded panel with hole.

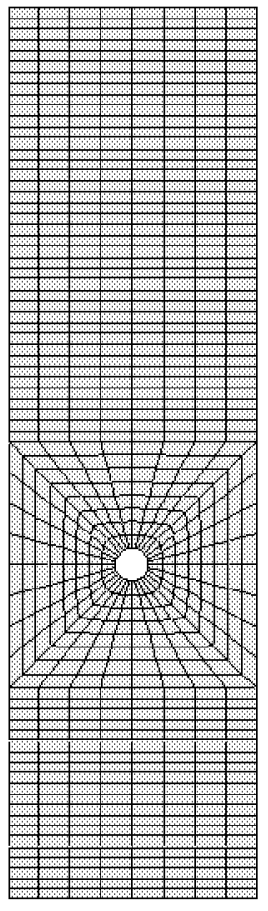

(a) Conventional model

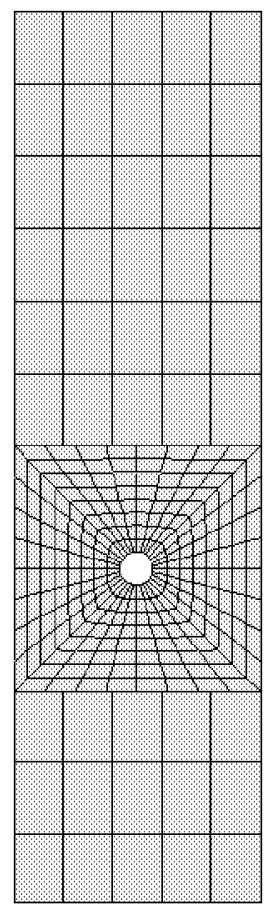

(b) Interface technology model

Figure 9- Finite element models of compression-loaded panel with hole. 


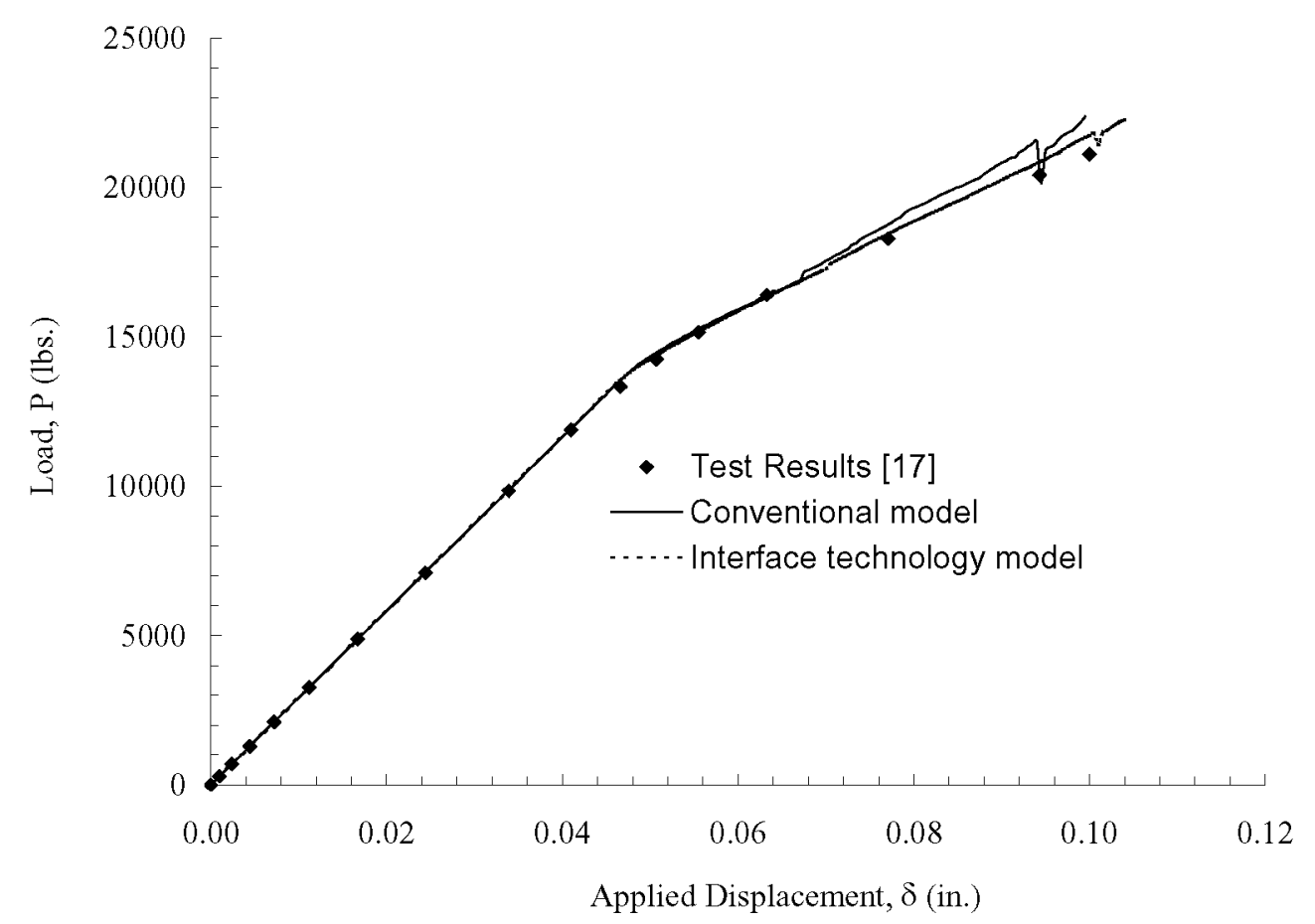

Figure 10- Load-deflection response for compression-loaded panel with hole.

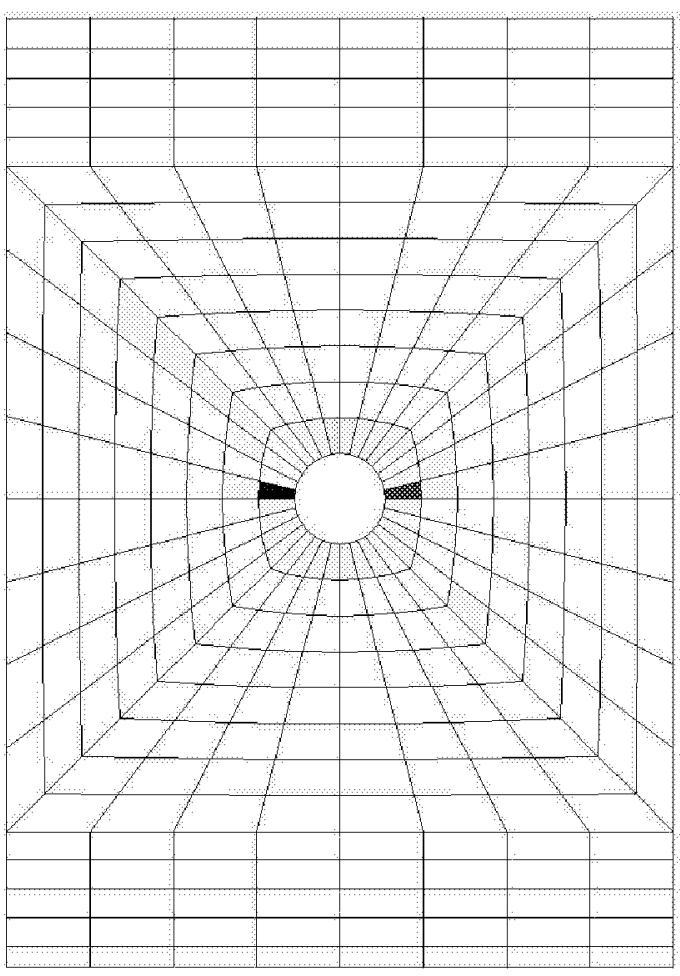

(a) Conventional model

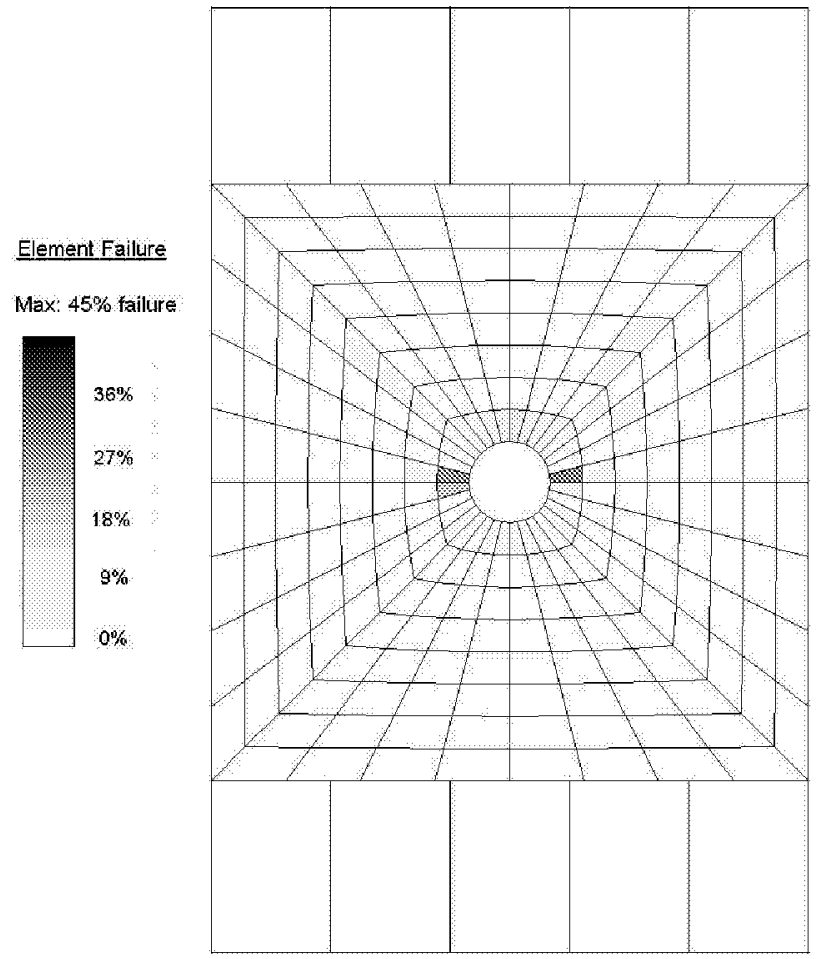

(b) Interface technology model

Figure 11- Percentage of element failure of compression-loaded panel with hole at final failure. 